\title{
Degradation of tocopherols during rapeseed storage in simulated conditions of industrial silos**
}

\author{
Marzena Gawrysiak-Witulska ${ }^{1}$, Aleksander Siger ${ }^{2}$, and Robert Rusinek ${ }^{3 *}$ \\ ${ }^{1}$ Institute of Food Technology, ${ }^{2}$ Department of Biochemistry and Food Analysis; \\ Poznań University of Life Sciences, Wojska Polskiego 28, 60-637 Poznań, Poland \\ ${ }^{3}$ Institute of Agrophysics, Polish Academy of Science, Doświadczalna 4, 20-290 Lublin, Poland
}

Received July 14, 2015; accepted November 17, 2015

\begin{abstract}
A b s t $\mathrm{r}$ a c t. The investigations consisted in laboratory simulation of conditions prevailing in the real ecosystem in an industrial rapeseed storage facility. The aim of the study was to assess the impact of temperature, moisture, and static pressure on degradation of tocopherols contained in rapeseed. Rapeseed varieties with high oil content were analysed in the investigations. Samples of seeds with $7,10,13$, and $16 \%$ moisture levels were stored at a temperature of 25,30 , and $35^{\circ} \mathrm{C}$ in specially designed airtight pressure silos for storage in controlled conditions. During the storage, the seeds were subjected to overpressure in the range of $20-60 \mathrm{kPa}$. The seeds were stored in these conditions for 28 days. It was demonstrated that primarily moisture induced the greatest loss of the total content of tocopherol and its $\alpha$-T and $\gamma$-T homologues, followed by temperature and, to a lesser extent, pressure. In addition, the results obtained showed that, in the case of seeds characterised by higher moisture levels (13 and 16\%), an increase in the storage temperature in the range of $25-30^{\circ} \mathrm{C}$ rather than $30-35^{\circ} \mathrm{C}$ intensified tocopherol loss more efficiently.
\end{abstract}

$\mathrm{K}$ e y w o r d s: rapeseed, postharvest, storage, tocopherols

\section{INTRODUCTION}

Over the last 20 years, the annual rapeseed production has increased and reached 72.5 million tons, with 25.5 million tons produced in Europe. With the annual production rates of 2.7 million tons, Poland is one of the leading producers of rapeseed in Europe (http://www.faostat.fao.org). For many years, rapeseed has been the object of many research programmes focused on improvement of the species. The ongoing research has led to development and introduction for cultivation of the so-called double-zero varieties with reduced contents of not only erucic acid $(<2 \%)$, but also glucosinolates. The investigations also resulted in deve-

*Corresponding author e-mail: r.rusinek@ipan.lublin.pl

**This work was supported by the National Centre for Research and Development (NCBR), Grant No. PBS2/ A8/22/2013. lopment of varieties with desired proportions of fatty acids and increased levels of biologically active compounds $e g$ sterols and tocopherols. Among the available types of oil, rapeseed oil is characterised by the most optimal proportion of omega- 6 and omega-3 acids recommended by nutritionists (Booth and Gunstone, 2004; Mollers and Gunstone 2004, Rękas et al., 2015). Current technologies of phytosterol pathway engineering can provide a two- to threefold increase in the phytosterol levels of oil seeds (Meyer et al., 2009). Currently, rapeseed is a valuable raw material for production of oil (Rusinek et al., 2012; Wroniak, 2012; Wroniak and Rękas, 2015). The by-products obtained during oil production can be used as valuable high-protein feed (Gornas, 2015).

The quality of rapeseed oil depends primarily on the condition of seeds used in production; therefore, seeds should be properly preserved after harvest. Rapeseed harvested in Poland usually exhibits a moisture level of 7-17 and $80-90 \%$ of the raw materials require cleaning and drying (Rybacki et al., 2001). In Poland, it is recommended that rapeseed intended for long-term storage should be dried to a moisture level of 7\% (Kasprzycka et al., 2010). After the drying process, rapeseed should be cooled down. Next, seeds should be safely stored in order to ensure continuity of industrial oil production. Most frequently, rapeseed is stored in containers and silos, which provide a certain ecosystem. During long-term rapeseed storage, maintenance of suitable temperature-moisture conditions is essential; hence, constant monitoring of the rapeseed condition is very important (Rusinek and Kobyłka, 2014). Drying and cooling of rapeseed does not guarantee safe, long-term storage thereof, since migration of moisture caused by

(C) 2016 Institute of Agrophysics, Polish Academy of Sciences 
heating of southern silo walls can take place. Consequently, warmer seed layers are slightly drier while the cooler layers undergo re-wetting, which may also be related to improper maintenance of the silo air inlet (Ryniecki, 2005). The increased water content in seeds intensifies seed respiration, enhances the activity of enzymes contained therein, and promotes growth of microflora, which leads to heating of the seed mass in some conditions (Pronyk et al., 2006). The consequences of a temperature increase comprise acceleration of the rate of adverse chemical and biochemical transformations occurring in seeds. A temperature rise to $30^{\circ} \mathrm{C}$ increases the content of products of hydrolysis and lipid oxidation in rapeseed and affects the fatty acid profile (Krasucki et al., 2002). In the case of rapeseed, these phenomena are intensified by the high content of fat, which enhances adverse biological and chemical processes, particularly in damaged seeds and the more delicate seed coat. In damaged seeds, increased microbial activity leads to deterioration of the quality or even destruction of the raw material. These phenomena are particularly dangerous to moist and overloaded seeds exposed to excess storage temperature, the local high gradients of which may result from impaired ventilation (Tys and Rybacki, 2001).

Rapeseed oil is a rich source of vitamin-E active compounds (Gawrysiak-Witulska et al., 2009). With their properties, they play an important role in eg prophylaxis of cardiovascular diseases (Rimm et al., 1993). Tocopherols are involved in the stability of lipids in stored seeds and determine the proper nutritional value of extracted oils (Hofius et al., 2003). Four homologues, $\alpha-, \beta-, \gamma-$, and $\delta$-, are distinguished among rapeseed tocopherols, with $\alpha-\mathrm{T}$ and $\gamma-\mathrm{T}$ occurring in the amount of $800 \mathrm{mg} \mathrm{kg}^{-1}$ of oil and the other two present in trace amounts (Ratnayake and Daun, 2004). During each stage of post-harvest processing (drying and storage), the content of bioactive compounds is degraded. The degradation rate depends on the conditions of rapeseed drying or storage. Investigations conducted by GawrysiakWitulska et al. (2009) showed a significant impact of the drying conditions, varietal differences, and duration of storage on the content of tocopherols in the black-seeded rapeseed variety. The method of low-temperature seed drying induced a $6-11 \%$ decline in the tocopherol content, whereas drying with temperatures in the range of $60-120^{\circ} \mathrm{C}$ yielded a $4-8 \%$ decrease. One-year storage of dried seeds at a temperature of $10^{\circ} \mathrm{C}$ caused further losses. In investigations concerning drying the seed of the yellow-seeded variety, tocopherol losses were reported to reach $23 \%$ in the process of air-drying at $120^{\circ} \mathrm{C}$ (Gawrysiak-Witulska et al., 2015). Furthermore, there have been investigations of tocopherol losses caused by improper conditions of rapeseed storage (moisture $10-15.5 \%$ and temperature $25-30^{\circ} \mathrm{C}$ ) (Gawrysiak-Witulska et al., 2011).

During seed storage in a silo, the lower layers of rapeseed are under the impact of static pressure exerted by the upper layers. There are no data about the effect of changes in this parameter on the content of bioactive compounds during rapeseed storage. Therefore, the aim of these investigations was to make a laboratory simulation of a real ecosystem present inside an industrial facility and assess the effect of not only temperature and moisture but also static pressure on degradation of tocopherols contained in rapeseed during storage.

\section{MATERIALS AND METHODS}

In the investigations, high-oil rapeseed suitable for cold pressing was used. Prior to each experiment, the seeds were moistened to the predetermined moisture level. To this end, the seeds were sprayed with a suitable amount of water calculated from the mass balance. Next, the sample was stirred in a laboratory stirrer for $24 \mathrm{~h}$ at a temperature of $8^{\circ} \mathrm{C}$ in order to equalise the seed moisture content in the entire volume. Afterwards, seed moisture was checked twice before the beginning of the experiment. Four levels of moisture were tested in the experiments ie 7, 10,13, and 16\%.

After humidification, the seeds were stored in specially designed airtight pressure silos for rapeseed storage in controlled conditions. The pressure silos allowed storage of seed samples in a temperature range from 7 to $70^{\circ} \mathrm{C}$ and a pressure value up to $400 \mathrm{kPa}$. The capacity of the silo was $0.23 \mathrm{~m}^{3}$ and the weight was $215 \mathrm{~kg}$. The equipment facilitated conducting the experiments in aerobic and anaerobic conditions. The analyses were performed using $0.5 \mathrm{~kg}$ seed samples. Moistened seeds were placed in PVC bags and transferred to rubber sleeves made of thin latex rubber. The foil layer prevented chemical reactions between latex and fat. Samples prepared in this way were sealed hermetically with a Teflon plug with inserted flow tubes, the outlets of which were placed outside the silo. To meet the requirements of the investigation programme, there was a possibility of opening or closing the tubes to provide aerobic or anaerobic conditions, respectively. Each sample was monitored on-line in the silo by means of temperature and moisture sensors placed in intergranular spaces as well as by carbon dioxide sensors. The samples were transferred into the container, which was hermetically closed and the predetermined storage parameters were applied. The tested overpressure was applied in the range of 20,40 , and $60 \mathrm{kPa}$ at temperature values of 25,30 , and $35^{\circ} \mathrm{C}$. The values of static pressure affecting the samples in the rubber sleeve corresponded to actual conditions prevailing in silos. Calculations of the pressure of the top seed layers were carried out for a typical reinforced concrete silo with capacity of about $8000 \mathrm{~m}^{3}$. The seeds were stored in anaerobic conditions for 28 days.

The seed moisture content was determined using an electronic moisture analyser (MA150 Sartorius Mechatronics, Poland). The moisture analyser used a reference standard prepared by drying a $5 \mathrm{~g}$ sample to constant mass at a temperature of $105^{\circ} \mathrm{C}$. The measuring accuracy of the analyser 
was $0.05 \%$ (w.b.). The moisture analyser was calibrated with the oven method according to the AOCS Official Method Ba 2a-38 (AOCS Official Method Ba 2a-38, 2007) using the prepared reference as mentioned above.

Samples of seeds $(2 \mathrm{~g})$ were saponified using $60 \% \mathrm{KOH}$ $(2 \mathrm{ml})$, ethanol $(20 \mathrm{ml})$ and pyrogallol $(0.5 \mathrm{~g})$. Saponification was carried out at the ethanol boiling point temperature $\left(78^{\circ} \mathrm{C}\right)$ for $30 \mathrm{~min}$. After saponification, unsaponifiable substances were extracted using $50 \mathrm{ml}$-hexane/ethyl acetate $(90: 10 \mathrm{v} / \mathrm{v}) .100 \mathrm{ml}$ of the organic layer (unsaponifiable) were collected for high-performance liquid chromatography (Waters 600 Milford, MA, USA). A LiChrosorb Si60 column $(250 \times 4.6 \mathrm{~mm}, 5 \mu \mathrm{m})$ was used. The mobile phase consisted of $n$-hexane and 1.4-dioxane $(96: 4 \mathrm{v} / \mathrm{v})$. The flow rate was $1.0 \mathrm{ml} \mathrm{min}{ }^{-1}$. The fluorometric detector (Waters 474 Milford, MA, USA) worked at excitation at $295 \mathrm{~nm}$ and emission at $330 \mathrm{~nm}$ (Gawrysiak-Witulska et al., 2001). Tocopherols ( $\alpha$-T, $\beta$-T, $\gamma$-T, $\delta$-T) were identified by compa- rison of retention time, and concentrations were calculated by comparison of the area values with values from exterior standard tocopherols (Merck, Darmstadt, Germany).

In order to determine the influence of pressure, temperature, and moisture on tocopherol degradation during storage, a multiple analysis of variance was performed. For the significance factors, post-hoc tests (Tukey) were additionally performed to determine homogenous groups. All tests were considered significant at $p<0.05$. The analysis was performed by Statistica V.10 (StatSoft, Inc., USA) package.

\section{RESULTS AND DISCUSSION}

Changes in the total content of tocopherol, its homologues, and plastochromanol-8 are presented in Figure 1. In rapeseed intended for storage (control), the total tocopherol content was $460.51 \mathrm{mg} \mathrm{kg}^{-1}$ (Fig. 1a). As reported by Dolde et al. (1999), the total tocopherol content in rapeseed is characterised by great variability and is largely

Moisture

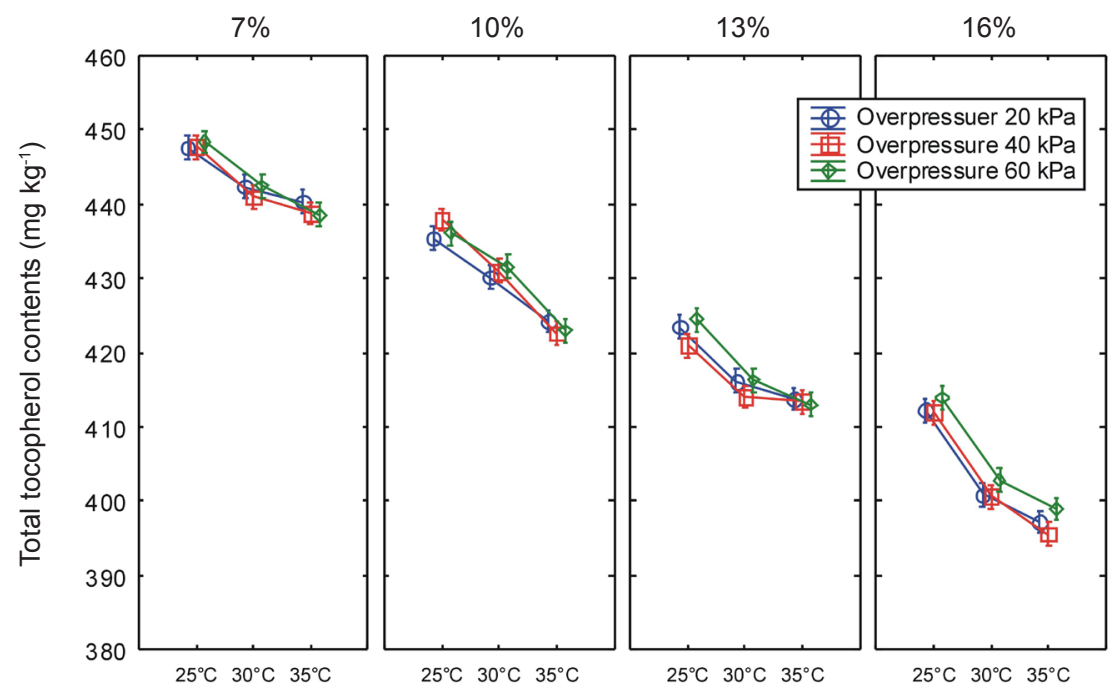

b

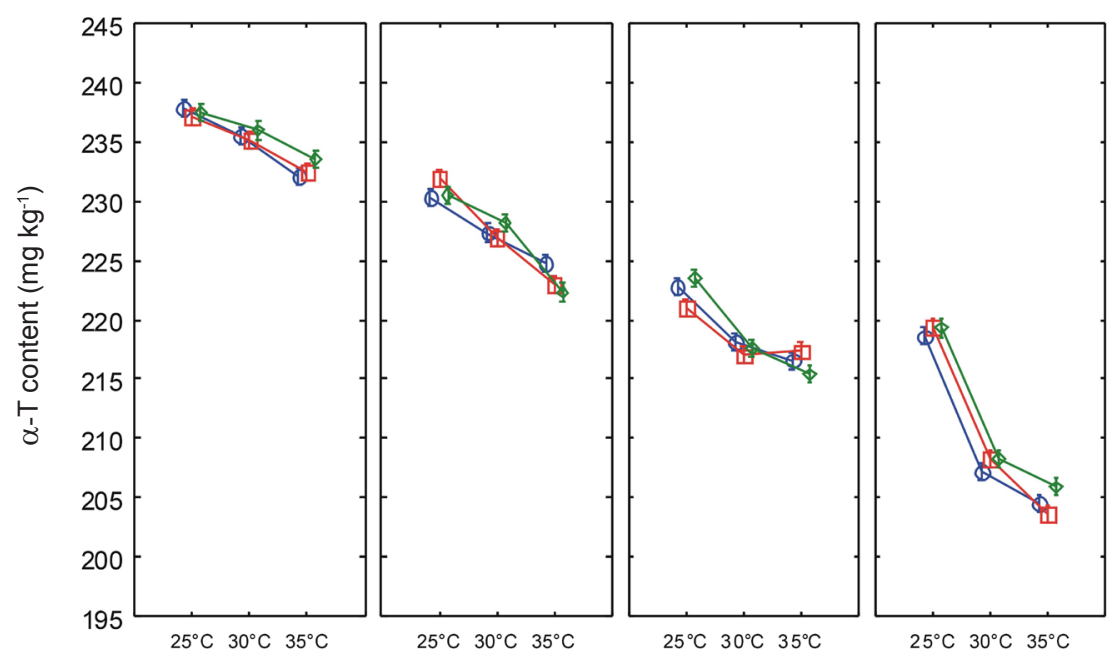

Fig. 1. The effects of rapeseed storage conditions on: $\mathrm{a}-$ total tocopherol, $\mathrm{b}-\alpha-\mathrm{T}, \mathrm{c}-\gamma-\mathrm{T}$, and $\mathrm{d}-\mathrm{PC}-8$ contents. 
c

d

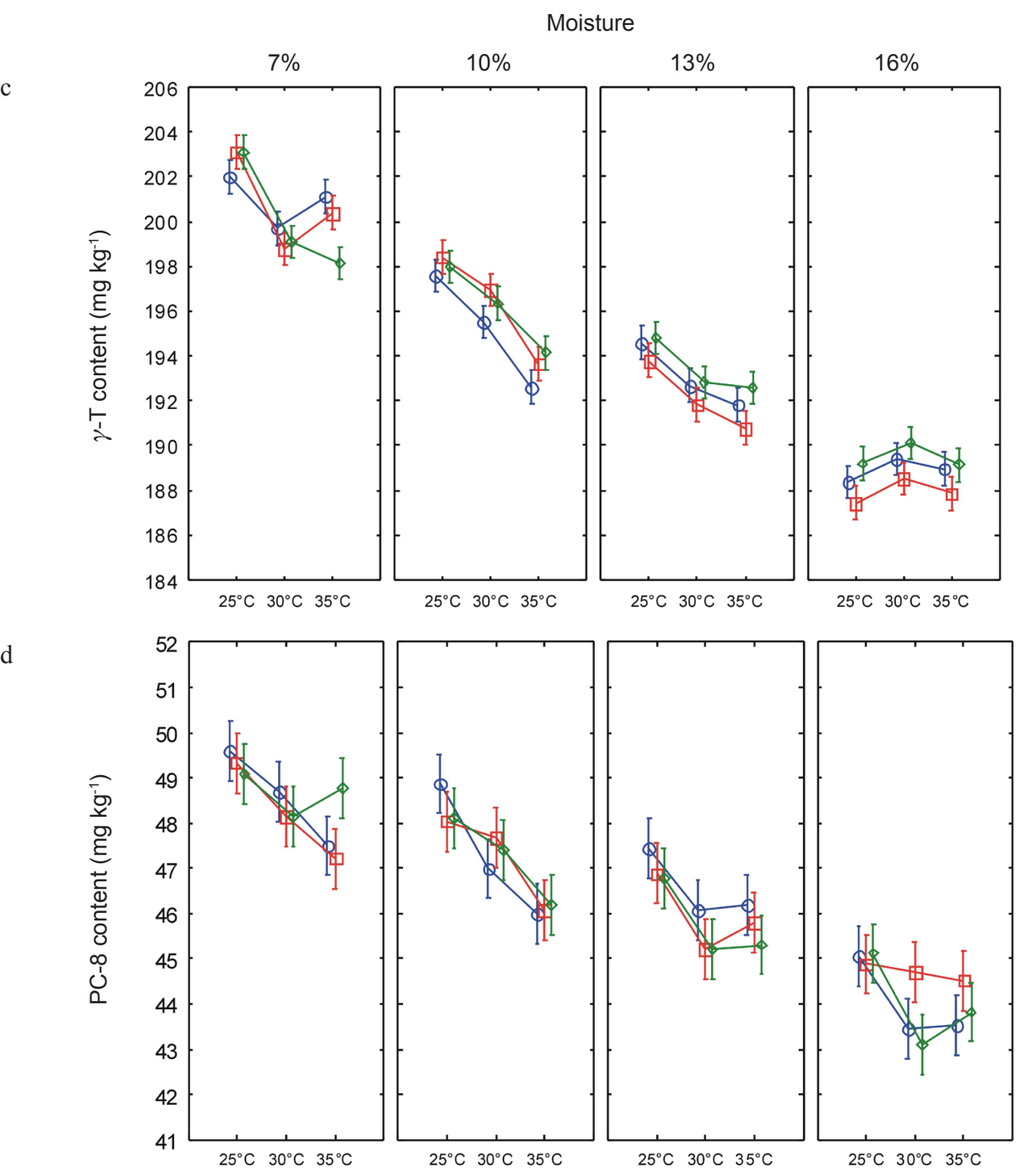

Fig. 1. Continuation.

dependent on changes in the environmental conditions. Its content may vary in the range of $80-1000 \mathrm{mg} \mathrm{kg}^{-1}$. The percent proportion of the tocopherol fraction in the control sample was characteristic for that in rapeseed oil. The dominant tocopherol was the $\alpha$-T homologue (242.4 $\mathrm{mg} \mathrm{kg}^{-1}$ ), which constituted $53 \%$ of the total content of tocopherols. The content of $\gamma$-T was $207.1 \mathrm{mg} \mathrm{kg}^{-1}(45 \%)$. The other tocopherol homologues were present in substantially lower amounts and accounted for up to $2 \%$. Similarly, Marwede et al. (2004) and Gawrysiak-Witulska et al. (2011) showed in their papers that the $\alpha$-T and $\gamma$-T homologues were the dominant tocopherols in rapeseed. As shown by GawrysiakWitulska et al. (2011), depending on the variety, $\alpha$-T constituted $36-41 \%$ of the total tocopherol content, while $\gamma-\mathrm{T}$ accounted for $57-62 \%$. In the samples intended for storage, the $\alpha$-T to $\gamma$-T ratio was estimated at 1.17 (Table 1). As reported by Marwede et al. (2004), the $\alpha$-T to $\gamma$-T ratio in rapeseed ranges from 0.54 to 1.7 . Investigations conducted by Gawrysiak-Witulska et al. $(2009,2011)$ confirm this relationship.

During storage in the established overpressure and temperature conditions, the total tocopherol content in the seeds characterised by different moisture levels declined by $3-14 \%$. The greatest loss (13-14\%) was noted in seeds stored at $16 \%$ moisture and $35^{\circ} \mathrm{C}$. In these seeds, the tocopherol content determined after the end of the experiment was $397.2(20), 395.6(40)$, and $398.9 \mathrm{mg} \mathrm{kg}^{-1}$ (60 kPa). Seed storage at $16 \%$ moisture, temperatures of 25 and $30^{\circ} \mathrm{C}$, and $20-60 \mathrm{kPa}$ overpressure resulted in $10-13 \%$ loss of the total tocopherol content. The losses increased with the increasing storage temperature. The smallest loss of the total tocopherol content was noted in seeds stored at $7 \%$ moisture and a temperature of $25^{\circ} \mathrm{C}(20-60 \mathrm{kPa})$. In these samples, the tocopherol content estimated after the experiment declined to a level of $447.6-448.39 \mathrm{mg} \mathrm{kg}^{-1}$ (3\%). 
T a b l e 1. $\alpha-\mathrm{T} / \gamma$-T ratio for stored rapeseed

\begin{tabular}{|c|c|c|c|c|c|c|c|c|c|c|c|c|}
\hline \multirow{4}{*}{$\begin{array}{l}\text { Over- } \\
\text { pressure } \\
(\mathrm{kPa})\end{array}$} & \multicolumn{12}{|c|}{ Temperature $\left({ }^{\circ} \mathrm{C}\right)$} \\
\hline & \multicolumn{4}{|c|}{25} & \multicolumn{4}{|c|}{30} & \multicolumn{4}{|c|}{35} \\
\hline & & & & & \multicolumn{4}{|c|}{ Moisture (\%) } & & & & \\
\hline & 7 & 10 & 13 & 16 & 7 & 10 & 13 & 16 & 7 & 10 & 13 & 16 \\
\hline Control & 1.17 & 1.17 & 1.17 & 1.17 & 1.17 & 1.17 & 1.17 & 1.17 & 1.17 & 1.17 & 1.17 & 1.17 \\
\hline 20 & 1.18 & 1.17 & 1.14 & 1.16 & 1.18 & 1.16 & 1.13 & 1.09 & 1.15 & 1.17 & 1.13 & 1.08 \\
\hline 40 & 1.17 & 1.17 & 1.14 & 1.17 & 1.18 & 1.15 & 1.13 & 1.10 & 1.16 & 1.15 & 1.14 & 1.08 \\
\hline 60 & 1.17 & 1.18 & 1.15 & 1.16 & 1.19 & 1.16 & 1.13 & 1.10 & 1.18 & 1.15 & 1.12 & 1.09 \\
\hline
\end{tabular}

In the same seeds stored at 30 and $35^{\circ} \mathrm{C}$, the loss of the investigated compounds reached $4-5 \%$. After the storage period, seeds with the moisture level of $10 \%$ were characterised by a $5-8 \%$ decrease in the tocopherol content. As in the case of the seeds with the $16 \%$ moisture level, the losses increased with the rising storage temperature. After storage at $25^{\circ} \mathrm{C}$, seeds with the 13\% moisture content exhibited 8-9\% degradation of the total tocopherol content; in turn, the loss reached $10 \%$ in seeds stored at 30 and $35^{\circ} \mathrm{C}$. Investigations carried out by Gawrysiak-Witulska et al. (2011) showed $14.4 \%$ loss in the tocopherol content after 18-day storage of rapeseed with a moisture level of $15.5 \%$ at a temperature of $30^{\circ} \mathrm{C}$. Storage of seeds with the $10 \%$ moisture content in the same conditions resulted in $4 \%$ tocopherol losses. As reported by Gopalakrishnan et al. (1996), 10 day storage of crushed rapeseed at room temperature may cause a $50 \%$ reduction of the total tocopherol content. GawrysiakWitulska et al. (2009) showed a 23-30\% decline in the tocopherol level after one-year storage of seeds dried at $10^{\circ} \mathrm{C}$. Goffman and Möllers (2000) investigated changes in the tocopherol content in whole rapeseed stored at 5, 20, and $40^{\circ} \mathrm{C}$. The authors observed a decline in the tocopherol content only at a temperature of $40^{\circ} \mathrm{C}$.

This paper also presents analysis of degradation of tocopherol homologues induced by storage conditions (Fig. 1b, c). In the case of $\alpha$-T, likewise for the total tocopherol content, the greatest loss $(15-16 \%)$ was noted for seeds with the $16 \%$ moisture content stored at a temperature of $35^{\circ} \mathrm{C}$. In these samples, there was a decline in the $\alpha$-T level from 242.4 to $204.5 \mathrm{mg} \mathrm{kg}^{-1}(20 \mathrm{kPa})$, $203.6 \mathrm{mg} \mathrm{kg}^{-1}(40 \mathrm{kPa})$, and $205.9 \mathrm{mg} \mathrm{kg}^{-1}$ (60 kPa). Storage of seeds with $16 \%$ moisture caused slightly smaller losses of these compounds at $30^{\circ} \mathrm{C}(14-15 \%)$ and substantially smaller losses at $25^{\circ} \mathrm{C}(9-10 \%)$. The smallest $\alpha$-T loss was reported during storage of seeds with the $7 \%$ moisture level at $25^{\circ} \mathrm{C}$. In these samples, irrespective of the overpressure applied, the loss was estimated at $2 \%$. During storage of samples with the $7 \%$ moisture level, the $\alpha$-T loss increased to $3 \%$ at $30^{\circ} \mathrm{C}$ and to $4 \%$ at $35^{\circ} \mathrm{C}$ regardless of the overpressure applied. Degradation of $\alpha-T$ in the seeds with the $10 \%$ moisture content was in the range of $4-8 \%$ and increased with the rising storage temperature. The increase in the content of the stored seed moisture to $13 \%$ resulted in $10-11 \%$ loss of the compound. In a previous investigation by Gawrysiak-Witulska et al. (2011), $\alpha$-T losses in seeds with a $10 \%$ moisture level stored for 18 days at a temperature of 25 and $30^{\circ} \mathrm{C}$ were smaller ie $2-3 \%$. In this study, elevation of the moisture content in the stored seeds from 10 to $12.5 \%$ yielded nearly twofold $\alpha$-T loss at $25^{\circ} \mathrm{C}$ and threefold loss at $30^{\circ} \mathrm{C}$.

The losses in the $\gamma$-T homologue content noted during storage of seeds with the 7 and 10\% moisture levels at different temperature and pressure values were comparable to the losses noted for the $\alpha$-T homologue. In the seeds with the $13 \%$ moisture content, the degradation of the $\gamma$-T homologue in the established storage conditions was slower than that of $\alpha$-T and ranged between 5 and $8 \%$. Similar relationships were observed for stored seeds with $16 \%$ moisture, in which $8-10 \%$ losses were reported. Similarly, in the investigations of Gawrysiak-Witulska et al. (2011), during inappropriate storage of rapeseed, the degradation rate was lower for the $\gamma$-T homologue than in the case of $\alpha$-T. After 18-day storage of seeds with $10 \%$ moisture, the losses of this homologue ranged from 1.5 to $3 \%$ (at 25 and $30^{\circ} \mathrm{C}$, respectively). Storage of seeds with a $12.5 \%$ moisture level induced $4-5 \%$ losses of this compound, whereas in the seeds with $15.5 \%$ moisture the losses reached 6 and $12 \%$.

Multivariate analysis revealed the greatest impact of moisture followed by temperature and a slight effect of pressure on the losses of the total tocopherol content and the $\alpha-\mathrm{T}$ and $\gamma$-T homologue levels. Additionally, it showed an interaction between temperature and moisture. An increase in the moisture content intensified the losses caused by the increasing temperature. Simultaneously, the temperature rise enhanced the increase in the loss levels induced by the increase in the moisture content. Furthermore, at the low seed moisture level ( $7 \%$ ), a statistically significant effect of the higher pressure on $\gamma$-T degradation was observed. The investigation results also demonstrated that, in the case of rapeseed with the higher moisture contents (13 and 16\%), 
the increase in the storage temperature from 25 to $30^{\circ} \mathrm{C}$ enhanced tocopherol loss more efficiently than the temperature rise from 30 to $35^{\circ} \mathrm{C}$.

The higher rate of $\alpha$-T homologue degradation, compared with that of $\gamma$-T, is clearly indicated by the change in the $\alpha-T / \gamma-T$ ratio value (Table 1 ). The largest decrease in its value $i e$ from 1.17 to $1.08-1.1$, was observed during storage of the seeds with $16 \%$ moisture at 30 and $35^{\circ} \mathrm{C}(20-60 \mathrm{kPa})$. The investigations conducted by Gawrysiak-Witulska et al. (2009) indicated a faster rate of degradation of the $\gamma$-T than $\alpha-\mathrm{T}$ homologue during one-year storage of seeds with $7 \%$ moisture (recommended for long-term storage) at a temperature of $10 \pm 2^{\circ} \mathrm{C}$, which resulted in an increase in the $\alpha-\mathrm{T} / \gamma$-T ratio from 0.7 to 1.0 , depending on the variety and the drying method employed. In further research of tocopherol degradation caused by improper storage of rapeseed, Gawrysiak-Witulska et al. (2011) reported a higher rate of the $\alpha$-T homologue, compared with $\gamma$-T.

Rapeseed also contains PC-8, which has a chromanol ring identical to the $\gamma$-T homologue, although it has a longer side chain ( 8 isoprene units) and, as such, is classified as a derivative of gamma-tocotrienol ( $\gamma$-T3) (Przybylski and Mag, 2002). The initial content of this compound in the rapeseed was $53.4 \mathrm{mg} \mathrm{kg}^{-1}$. The level of the compound assessed after the storage period is presented in Fig. 1c. The increased seed moisture and storage temperature contributed to losses of the content of this compound, which proved to be less stable in the experimental conditions than tocopherols. The greatest PC-8 losses (16-19\%) were noted for seeds with the $16 \%$ moisture level stored at the temperature range of $25-35^{\circ} \mathrm{C}$. The smallest PC-8 losses (7-8\%) were observed in seeds with the $7 \%$ moisture level stored at $25^{\circ} \mathrm{C}(20-60 \mathrm{kPa})$. In these samples, the content of PC-8 estimated after the storage process declined to the level of $49.09-49.6 \mathrm{mg} \mathrm{kg}^{-1}$. In the same rapeseed stored at 30 and $35^{\circ} \mathrm{C}$, the losses of the investigated compound reached $7-11 \%$. After the storage period, seeds with the $10 \%$ moisture level exhibited an 8-14\% decrease in the PC-8 content. In previous studies, Gawrysiak-Witulska et al. (2011) showed that PC-8 losses were higher than the losses of the total tocopherol content after 18-day storage of rapeseed at a moisture level of $10,12.5$, and $15.5 \%$ and a temperature of 25 and $30^{\circ} \mathrm{C}$. Similarly, research conducted by Goffman and Möllers (2000) demonstrated that PC-8 was degraded more readily than tocopherols during storage of whole rapeseed. PC- 8 losses have also been noted during the process of yellow-seeded rapeseed drying (Gawrysiak-Witulska et al., 2015). However, detailed analysis showed that PC-8 losses induced by air-drying at a temperature of $40-60^{\circ} \mathrm{C}$ were greater than those of total tocopherols; in turn, at $100-120^{\circ} \mathrm{C}$ drying, the losses were smaller than those found for total tocopherols. In the analysed rapeseed, there were no tocotrienols, which have equal or higher antioxidant activity but lower vitamin E activity than tocopherols, as reported by Rippert et al. (2004).

\section{CONCLUSIONS}

1. The results have shown that inadequate conditions of storage of rape seed for oil production can significantly reduce the value of nutritional compounds - tocopherols in the rapeseed and, hence, in the end product.

2 . The greatest impact of moisture followed by temperature and a slight effect of pressure on the losses of the total tocopherol content as well as the $\alpha-\mathrm{T}$ and g-T homologues have been demonstrated.

3. The results have also revealed that, in the case of seeds with the higher moisture levels ( 13 and $16 \%$ ), the $25-30^{\circ} \mathrm{C}$ rise in storage temperature intensifies tocopherol loss more efficiently than the $30-35^{\circ} \mathrm{C}$ temperature increase.

\section{REFERENCES}

Booth E.J. and Gunstone F.D. (Ed.), 2004. Rapeseed and canola oil. In: Production, Processing. Properties and Uses Blackwell Publishing, Oxford, UK.

Dolde D., Vlahakis C., and Hazebrock J., 1999. Tocopherols in breeding lines and effects of planting location, fatty acid composition and temperature during development. J. Am. Oil Chem. Soc., 76, 349-355.

Gawrysiak-Witulska M., Rudzińska M., Siger A, and Bartkowiak-Broda I., 2015. A high drying temperature causes degradation of sterols and tocopherols in yellowseeded Brassica napus oils. Eur. J. Lipid Sci. Technol., 117, 483-490.

Gawrysiak-Witulska M., Siger A., and Nogala-Kalucka M., 2009. Degradation of tocopherols during near-ambient rapeseed drying. J. Food Lipid., 16, 524-539.

Gawrysiak-Witulska M., Siger A., Wawrzyniak J., and Nogala-

Kałucka M., 2011. Changes in tocochromanol content in seeds of Brassica napus L. during adverse conditions of storage. J. Am. Oil Chem. Soc., 88, 1379-1385.

Goffman F.D. and Mollers C., 2000. Changes in tocopherol and plastochromanol-8 contents in seeds and oil of oilseed rape (Brassica napus L.) during storage as influenced by temperature and air oxygen. J. Agric. Food Chem., 48, 1605-1609.

Gopalakrishnan N., Cherian G., and Sim J.S., 1996. Chemical changes in the lipids of canola and flax seed during storage. Fett/Lipid 98, 168-171.

Gornas P., 2015. Unique variability of tocopherol composition in various seed oils recovered from by-products of apple industry: Rapid and simple determination of all four homologues $(\alpha, \beta, \gamma$ and $\delta$ ) by RP-HPLC/FLD. Food Chemistry, $172,129-134$.

Hofius D. and Sonnewald U., 2003. Vitamin E biosynthesis: biochemistry meets cell biology. Trends Plant Sci., 8, 6-8.

Kasprzycka A., Skiba K., and Tys J., 2010. Influence of storage conditions on microbial quality of rapeseed cake and middings. Int. Agrophys., 24, 261-265.

Krasucki W., Tys J., Szafran K., Rybacki R., and Orlicki Ł., 2002. Influence of drying temperature on chemical composition of seeds of oilseed rape. Oilseed Crops, 23, 427-438.

Marwede V., Schierholt A., Mollers C., and Becker H.C., 2004. Genotype $\mathrm{X}$ environment interactions and heritability of tocopherol contents in canola. Crop Sci., 44, 728-731. 
Meyer K. and Kinney A.J., 2009. Lipids in photosynthesis. In: Advances in Photosynthesis and Respiration (Eds H. Wada, N. Murata). Springer Science + Business media, B.V., Dordrecht, the Netherlands.

Möllers C. and Gunstone F.D. (Ed.), 2004. Rapeseed and Canola oil. In: Production, Processing, Properties and Uses Blackwell Publishing, Oxford, UK.

Pronyk C., Abramson D., Muir W.E., and White N.D.G., 2006. Correlation of total ergosterol levels in stored canola with fungal deterioration. J. Stored Prod. Res., 42, 162-172.

Przybylski R. and Mag T., 2002. Vegetable Oils in Food Technology (Ed. F.D. Gunstone). Composition, Properties and Uses Blackwell Publishing Ltd., Oxford, UK.

Ratnayake W.M.N. and Daun J.K., 2004. Rapeseed and canola oil (Ed. F.D. Gunstone). Processing, Properties and Uses Blackwell Publishing, Oxford, UK.

Rękas A., Wroniak M., and Rusinek R., 2015. Influence of roasting pretreatment on high-oleic rapeseed oil quality evaluated by analytical and sensory approaches. Int. J. Food Sci. Technol., 50(10), 2208-2214.

Rimm E.B., Stampfer M.J., Ascherio A., Giovannucci E., Colditz G.A., and Willett W.C., 1993. Vitamin E consumption and the risk of coronary heart disease in men. N. Engl. J. Med., 328, 1450-1456.
Rippert P., Scimemi C., Dubald M., and Matringe M., 2004. Engineering plant shikimate pathway for production of tocotrienol and improving herbicide resistance. Plant Physiol., 134, 92-100.

Rusinek R. and Kobylka R., 2014. Experimental study and discrete element method modeling of temperature distributions in rapeseed stored in a model bin. J. Stored Prod. Res., 254-259.

Rusinek R., Rybczyński R., Tys J., Gawrysiak-Witulska M., Nogala-Kałucka M., and Siger A., 2012. The process parameters for non-typical seeds during simulated cold deep oil expression. Czech J. Food Sci., 30(2), 126-134.

Rybacki R., Skawiński P., and Lampkowski M., 2001. The status of rapeseed dehydration in the raw material base area of ZT Kruszwica S.A. (in Polish). Oilseed Crops, 22, 539-549.

Ryniecki A., 2005. Drying and Cooling Grain in Bulk - Handbook (Part 1). Mr Info, Poznań, Poland and KBN Handelsselskab v/Karlo B. Nielsen, Esbjerg, Denmark.

Tys J. and Rybacki R., 2001. Rapeseed - seed quality. Harvesting, drying and storage processes. Acta Agrophysica, 44, 33-38.

Wroniak M., 2012. Nutritional value of cold-pressed rapeseed oils. Food Sci. Technol. Quality, 19(6), 79-92.

Wroniak M. and Rękas A., 2015. Nutritional value of cold-pressed rapeseed oil during long term storage as influenced by the type of packaging material, exposure to light \& oxygen and storage temperature. DOI: 10.1007/s13197-015-2082-y. 